204

Reihe Ökonomie

Economics Series

\title{
Keeping up with the Ageing Joneses
}

Walter H. Fisher, Ben J. Heijdra 

Reihe Ökonomie Economics Series

\section{Keeping up with the Ageing Joneses}

Walter H. Fisher, Ben J. Heijdra

March 2007

Institut für Höhere Studien (IHS), Wien Institute for Advanced Studies, Vienna 


\section{Contact:}

\section{Walter H. Fisher}

Department of Economics and Finance

Institute for Advanced Studies

Stumpergasse 56

1060 Vienna, Austria

푤: +43/1/599 91-253

Fax: +43/1/599 91-555

Email: fisher@ihs.ac.at

Ben J. Heijdra

Department of Economics

University of Groningen

P.O. Box 800

9700 AV Groningen, The Netherlands:

용: $+31 / 50 / 363-7303$

Fax: +31/50/363-7337

Email: b.j.heijdra@rug.nl

and

Institute for Advanced Studies

Stumpergasse 56

1060 Vienna, Austria

Founded in 1963 by two prominent Austrians living in exile - the sociologist Paul F. Lazarsfeld and the economist Oskar Morgenstern - with the financial support from the Ford Foundation, the Austrian Federal Ministry of Education and the City of Vienna, the Institute for Advanced Studies (IHS) is the first institution for postgraduate education and research in economics and the social sciences in Austria. The Economics Series presents research done at the Department of Economics and Finance and aims to share "work in progress" in a timely way before formal publication. As usual, authors bear full responsibility for the content of their contributions.

Das Institut für Höhere Studien (IHS) wurde im Jahr 1963 von zwei prominenten Exilösterreichern dem Soziologen Paul F. Lazarsfeld und dem Ökonomen Oskar Morgenstern - mit Hilfe der FordStiftung, des Österreichischen Bundesministeriums für Unterricht und der Stadt Wien gegründet und ist somit die erste nachuniversitäre Lehr- und Forschungsstätte für die Sozial- und Wirtschaftswissenschaften in Österreich. Die Reihe Ökonomie bietet Einblick in die Forschungsarbeit der Abteilung für Ökonomie und Finanzwirtschaft und verfolgt das Ziel, abteilungsinterne Diskussionsbeiträge einer breiteren fachinternen Öffentlichkeit zugänglich zu machen. Die inhaltliche Verantwortung für die veröffentlichten Beiträge liegt bei den Autoren und Autorinnen. 


\section{Abstract}

In this paper we consider the implications of relative consumption externalities in the Blanchard-Yaari overlapping generations framework. Unlike most of the macroeconomic literature that studies this question, the differences between agents, and, thus, in their relative position, persist in equilibrium. We show in our fixed employment model that consumption externalities lower consumption and the capital stock in long-run equilibrium, a result in sharp contrast to the recent findings of Liu and Turnovsky (2005). In addition, we solve for the intertemporal path of the economy to investigate its response to demographic shocks, specifically, to permanent changes in the birth and death rates.

\section{Keywords}

Relative consumption, overlapping generations, demographic shocks

\section{JEL Classification}

D91, E21 



\section{Contents}

1 Introduction 1

2 The Macroeconomy 4

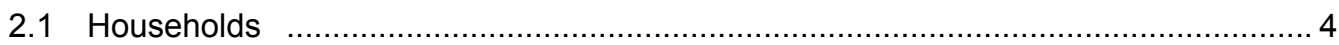

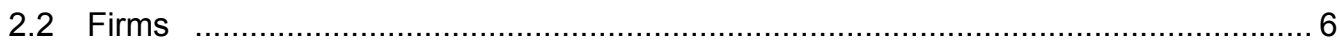

3 Aggregation and Macroeconomic Equilibrium 7

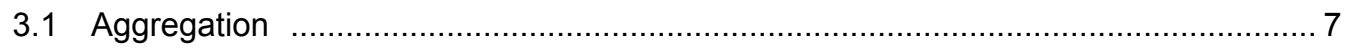

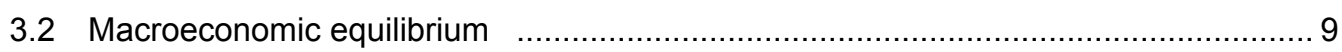

4 Log-Linearization and Model Solution 12

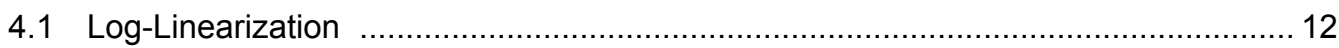

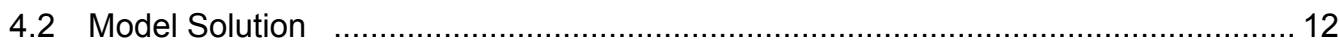

5 Comparative Dynamics 14

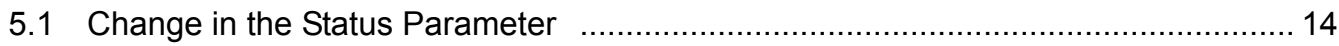

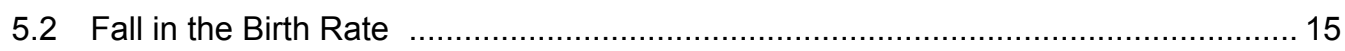

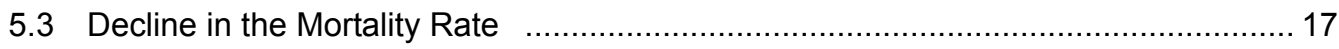

6 Conclusions and Extensions 19

$\begin{array}{ll}\text { Appendix } & 21\end{array}$

$\begin{array}{ll}\text { References } & 23\end{array}$ 



\section{Introduction}

Social scientists have long suggested that the drive for social position, or status, is a crucial motivation in economic decision making. In modern economics this idea has received general analytical treatments by authors such as Layard (1980) and Frank (1985, 1997), while empirical support for the importance of social position for economic well-being is found, for example, in the research of Easterlin $(1974,1995)$ and Oswald (1997).

Since the 1990s, this concept has also attracted the attention of macroeconomists, who have explored the implications of a preference for status on dynamic, aggregate behavior. Researchers focusing on the effects of status preference for macroeconomic equilibrium and growth include Rauscher (1997), Grossmann (1998), Fisher and Hof (2000), Dupor and Liu (2003), and Liu and Turnovsky (2005). These researchers assume that the quest for status - frequently referred to in this context as "Keeping-up-with-the Joneses" - is reflected in reduced-form specifications of individual preferences that depend on a benchmark level of consumption, such as the average, or aggregate, level of consumption in an economy. ${ }^{1}$ Among the questions these authors consider is whether, and under what circumstances, status preferences of this type cause agents to "over-consume" and work "too hard", compared to a hypothetical social optimum. In other words, does a welfare-reducing "rat race" result if individuals compare their own consumption to some economy-wide, benchmark level? For example, Liu and Turnovsky (2005), employing a standard representative agent (RA) setting, show that the long-run effects of consumption externalities depend on whether work effort is an endogenous variable: if, on the one hand, employment is fixed, then the steady state of the economy is independent of benchmark consumption, while, on the other, if work effort is endogenous, then consumption externalities lead to excessive long-run consumption and capital accumulation, as well as too much employment. ${ }^{2}$

Consumption externalities have also been used by authors such as Abel (1990) and Galí (1994), to study asset pricing, while Ljungqvist and Uhlig (2000) employ the "Catching-up-

\footnotetext{
${ }^{1}$ Another branch of the macroeconomic literature in this area assumes that social standing depends on relative wealth, rather than on relative consumption. See, for example, the recent work of Corneo and Jeanne (1997, 2001a, b), Futagami and Shibata (1998), Fisher (2004), Van Long and Shimomura (2004a, b), and Fisher and Hof (2005a, b).

${ }^{2}$ A similar result is found in Dupor and Liu (2003) and is attributable to the fact that consumption externalities raise the marginal rate of substitution for leisure above its Pareto optimal level.
} 
with-the-Joneses" version of status preferences in a simple business cycle model. ${ }^{3}$ More recently, this literature has been extended-particularly in terms of an analysis of the economy's transitional dynamics-by Alverez-Cuadrado et al. (2004), and Turnovsky and Monteiro (2007), who incorporate a time non-separable preference structure based on the fundamental work of Ryder and Heal (1973) on habit formation. ${ }^{4}$

While these studies have contributed many insights to our understanding of the aggregate implications of status preferences, the RA framework employed by all these researchers is, nevertheless, restrictive: since all agents are identical, all differences between them are eliminated in the symmetric macroeconomic equilibrium. In other words, no one "wins" the rat race in this context. In view of the fact, however, that status inherently concerns economic differences among individuals, it is important, in our view, to develop a macroeconomic model of social position in which these differences persist over time. Moreover, some crucial effects of consumption externalities might be lost in a symmetric economic equilibrium.

A natural starting point to model agent heterogeneity is the overlapping generations (OLG) framework in which individuals differ in age and, thus, in their consumption levels and asset holdings. In particular, the economic positions of agents differ from the corresponding economy-wide averages in this setting. To our knowledge, only the recent study of Abel (2005), who uses a discrete-time Diamond (1965) approach, considers the effects of benchmark consumption in an OLG setting. ${ }^{5}$ In contrast, we employ the Blanchard (1985)Yaari (1965) framework in our model of status preference. An important advantage of the Blanchard-Yaari (BY) approach is that it allows us to calculate detailed dynamic responses to macroeconomic disturbances.

The BY framework has been employed to study a wide variety of public policy and ag-

\footnotetext{
${ }^{3}$ Under the Catching-up-with-the-Joneses specification, which is also employed by Abel (1990), the benchmark level of consumption is weighted average of past consumption. In this context Ljungqvist and Uhlig (2000) show that the optimal consumption tax is countercyclical. In our model, the benchmark is the current consumption of all surviving generations.

${ }^{4}$ Both Alverez-Cuadrado et al. (2004), and Turnovsky and Monteiro (2007) employ an endogenous growth framework. Moreover, Turnovsky and Monteiro (2007) show that the results of Liu and Turnovsky (2005), regarding the conditions under which consumption externalities distort the economy's long run, extend to the time non-separable preference setting.

${ }^{5}$ Abel (2005) derives the balanced-growth optimal capital tax and transfer policy.
} 
gregate macroeconomic shocks in both closed and open economy contexts. ${ }^{6}$ Of immediate interest for our purposes are the recent applications of Heijdra and Ligthart (2006) and Bettendorf and Heijdra (2006), who study the dynamic implications of various demographic shocks. While Heijdra and Ligthart (2006) conduct their analysis in a general macroeconomic context with an endogenous employment decision, Bettendorf and Heijdra (2006) model the effects of demographic change on the pension system of an open economy that consumes and produces traded and non-traded goods. In this paper we follow these authors in modeling the impact of demographic shocks, focusing on the adjustment of aggregate consumption and the capital stock in our model of consumption externalities. ${ }^{7}$ Specifically, we consider the effects of a decline in the birth rate-a "baby bust" —and a fall in the mortality rate-a "longevity boost". In addition, we calculate the implications of an increase in the parameter determining the degree, or intensity, of status preference. Regarding the latter, a key finding of the paper is that the result of Liu and Turnovsky (2005)—-that the long-run equilibrium is independent of consumption externalities if employment is fixed-does not hold in the BY framework. We show, in fact, that negative consumption externalities lower both aggregate consumption and the capital stock in the long run, even though labor is exogenously supplied in our model.

The order of material in the remainder of the paper is as follows: the next section, section 2, analyzes the household and firm sectors. The OLG equilibrium is derived in section 3, which includes a phase diagram describing the macroeconomic dynamics. In section 4 we use our model to conduct macroeconomic experiments: i) an increase in the relative consumption parameter, ii) a decline in the birth rate, and iii) a fall in the mortality rate. Our analytical results regarding the economy's comparative dynamics are also supplemented in section 4 by numerical simulations. Section 5 briefly outlines our conclusions and suggestions for future work. Finally, a mathematical appendix contains some results used in the main text.

\footnotetext{
${ }^{6}$ In the context of tax and environmental policy see, for example, Bovenberg and Heijdra (1998). Representative applications of the BY framework in the open economy context include Frenkel and Razin (1986), Buiter (1987), and Obstfeld and Rogoff (1995).

${ }^{7}$ As in Heijdra and Ligthart (2006) and Bettendorf and Heijdra (2006), the demographic disturbances modeled in this paper are time-dependent, but cohort independent. For research that considers the implications of more realistic, cohort-specific demographic shocks, see the recent work of Heijdra and Romp (2006a, b).
} 


\section{The Macroeconomy}

\subsection{Households}

We begin this section with a description of household preferences and then proceed to an analysis of their intertemporal choices and constraints. As indicated above, we analyze an economy in which individuals of particular "vintages" care about their own consumption compared to the average prevailing level of consumption across generations. In other words, while young and old differ, they all aspire to the same level of consumption. For simplicity, we assume that agents supply a fixed amount of labor. The lifetime utility at time $t$ of an agent born at time $v$ (with $v \leq t$ ) is then given by:

$$
\Lambda(v, t)=\int_{t}^{\infty} U[\bar{c}(v, \tau), c(\tau)] e^{(\rho+\beta)(t-\tau)} d \tau,
$$

where $\bar{c}(v, \tau)$ is the individual level of consumption, $c(\tau)$ is the economy-wide level of consumption, $\rho$ is the rate of time preference, and $\beta$ is the instantaneous death probability. For simplicity, we use the following logarithmic felicity function:

$$
U[\cdot] \equiv \ln \bar{x}(v, \tau)
$$

where the subfelicity function $\bar{x}(v, \tau)$ is defined as follows:

$$
\bar{x}(v, \tau) \equiv \frac{\bar{c}(v, \tau)-\alpha c(\tau)}{1-\alpha}, \quad \alpha<1
$$

The key parameter $\alpha$ in (3) scales the importance of relative consumption. We allow $\alpha$ to take positive and negative values: if $\alpha>0$ then agents are "jealous" of the consumption of others, while if $\alpha<0$, then agents "admire" the consumption of others. Observe, in addition, that the specification of $\bar{x}(v, \tau)$ satisfies the condition stated in Liu and Turnovsky (2005), Proposition 3, for consumption externalities to have no effect on economic outcomes in the context of the RA, fixed employment framework. Thus, our use of (3) does not bias our results in favor of consumption externalities.

Agents receive interest income on their real asset holdings and real wage income from their exogenous labor supply. Their flow budget identity corresponds to:

$$
\dot{\bar{a}}(v, \tau)=[r(\tau)+\beta] \bar{a}(v, \tau)+w(\tau)-\bar{c}(v, \tau),
$$


where $\bar{a}(v, \tau)$ is real financial wealth, $r(\tau)+\beta$ is the annuity rate of interest, and $w(\tau)$ is the (age-independent) wage rate. Note that while each household supplies a single unit of labor, the (real) wage rate $w(\tau)$ is, in general, not constant over time.

As indicated above, we consider the implications of consumption externalities and demographic shocks in the overlapping generations framework, using an analytical solution of the model as well as numerical results. Applying standard methods, the following individual optimality condition is obtained for the time profile of subfelicity:

$$
\frac{\dot{\bar{x}}(v, \tau)}{\bar{x}(v, \tau)}=r(\tau)-\rho .
$$

To solve for the household's intertemporal budget constraint, we integrate the household budget identities, subject to $\bar{a}(v, t)$ taken as given, and obtain:

$$
\lim _{\tau \rightarrow \infty} \bar{a}(v, \tau) e^{-R(t, \tau)}-\bar{a}(v, t)=\int_{t}^{\infty} w(\tau) e^{-R(t, \tau)} d \tau-\int_{t}^{\infty} \bar{c}(v, \tau) e^{-R(t, \tau)} d \tau,
$$

where $R(t, \tau)$ is the annuity interest factor corresponding to:

$$
R(t, \tau) \equiv \int_{t}^{\tau}[r(s)+\beta] d s .
$$

Imposing the NPG condition, equal to $\lim _{t \rightarrow \infty} \bar{a}(v, \tau) e^{-R(t, \tau)}=0$, and using (3), equation (6) simplifies to:

$$
\int_{t}^{\infty}[(1-\alpha) \bar{x}(v, \tau)+\alpha c(\tau)] e^{-R(t, \tau)} d \tau=\bar{a}(v, t)+h(t),
$$

where $h(t)$ is age-independent human wealth:

$$
h(t)=\int_{t}^{\infty} w(\tau) e^{-R(t, \tau)} d \tau
$$

According to (8), the present discounted value of a weighted average of individual subfelicity and economy-wide per capita consumption equals the sum of the individual's financial and human wealth. Using (5), we next obtain an expression for $\bar{c}(v, t)$ in terms of $c(t)$ that is useful in determining the aggregate Euler equation. Solving (5) and noting (7) we find:

$$
\bar{x}(v, \tau)=\bar{x}(v, t) e^{R(t, \tau)-(\rho+\beta)(\tau-t)}, \quad \tau \geq t,
$$

which implies that the intertemporal budget constraint (8) can be written as:

$$
(1-\alpha) \bar{x}(v, t)+\alpha(\rho+\beta) \Gamma(t)=(\rho+\beta)[\bar{a}(v, t)+h(t)],
$$


where the term $\Gamma(t)$ is defined as:

$$
\Gamma(t) \equiv \int_{t}^{\infty} c(\tau) e^{-R(t, \tau)} d \tau
$$

Substituting the expression $(1-\alpha) \bar{x}(v, t)=\bar{c}(v, t)-\alpha c(t)$ from equation (3) into the intertemporal household budget constraint (11), we obtain the following relationship between individual, $\bar{c}(v, t)$, and average, $c(t)$, consumption:

$$
\bar{c}(v, t)=(\rho+\beta)[\bar{a}(v, t)+h(t)]+\alpha[c(t)-(\rho+\beta) \Gamma(t)] .
$$

In the absence of a consumption externality $(\alpha=0)$, individuals condition their consumption solely on their total wealth, with $\rho+\beta$ representing the propensity to consume out of total wealth. With a non-zero consumption externality, however, individual consumption is also directly affected by the future time path of economy-wide, per capita consumption. ${ }^{8}$

\subsection{Firms}

We next turn to the firm sector of economy, which is kept as simple as possible in order to focus on the implications of consumption externalities in the OLG framework. ${ }^{9}$ The production sector is characterized by a large number of firms that produce an identical good under conditions of perfect competition. Net ${ }^{10}$ output, $Y(t)$, is produced according to a Cobb-Douglas technology with labor, $L(t)$, and physical capital, $K(t)$, as homogeneous factor inputs that are rented from households:

$$
Y(t)=F[K(t), L(t)]=Z_{0} K^{\varepsilon} L^{1-\varepsilon}, \quad y(t)=Z_{0} k(t)^{\varepsilon}, \quad 0<\varepsilon<1,
$$

where $y(t) \equiv Y(t) / L(t)$ is per-capita output, $k(t) \equiv K(t) / L(t)$ is the capital-labor ratio, and $Z_{0}$ is exogenous total factor productivity. The production function possesses the

\footnotetext{
${ }^{8}$ We find from $(12)$ that $\dot{\Gamma}(t)=[r(t)+\beta] \Gamma(t)-c(t)$. Obviously, in the steady-state, we have that $\dot{\Gamma}(t)=0$ so that $\Gamma=c /(r+\beta)$. Using this result in the steady-state version of (13) yields:$$
\bar{c}(u)=(\rho+\beta)[\bar{a}(u)+h]+\alpha \frac{r-\rho}{r+\beta} c,
$$

where $u \equiv t-v$ is the agent's age. Since, $r>\rho$ (see below), provided $\alpha \neq 0$, aggregate consumption also influences individuals in the steady state.

${ }^{9}$ Similar to Liu and Turnovsky (2005), the present model can be extended to incorporate production as well as consumption externalities. We leave this task for future work.

${ }^{10}$ In other words, $Y(t)$ is measured taking into account the physical depreciation of the capital stock.
} 
standard features of positive but diminishing marginal products in both factors. The representative firm maximizes its net present (or equity) value:

$$
V(t)=\int_{t}^{\infty}[[Y(\tau)-w(\tau) L(\tau)]+\delta K(\tau)-I(\tau)] \exp \left[-\int_{t}^{\tau} r(s) d s\right] d \tau,
$$

with respect to labor and capital subject to the production function (14) and the capital accumulation constraint, $\dot{K}(t)=I(t)-\delta K(t)$, where $I(t)$ denotes gross investment, $w(t)$ is the economy-wide real wage, and $\delta$ is the constant rate of physical depreciation of capital. By assumption, there are no adjustment costs associated with investment. The first-order conditions for the firm imply that the marginal productivity of labor and capital equal the producer costs of these factors:

$$
\begin{aligned}
& F_{K}[k(t), 1]=\varepsilon y(t) / k(t)=r(t), \\
& F_{L}[k(t), 1]=(1-\varepsilon) y(t)=w(t) .
\end{aligned}
$$

Substituting the relationships (16)-(17) in (15) and using the CRS property of $F[K(t), L(t)]$, we can show, in addition, that the market value of the firm equals the replacement value of its capital stock, i.e., $V(t)=K(t){ }^{11}$

\section{Aggregation and Macroeconomic Equilibrium}

\subsection{Aggregation}

In this part of the paper we derive the aggregate relationships of the household sector and state the overall OLG macroeconomic equilibrium. We allow for constant population growth $n$ and distinguish between the birth rate, $\eta$, and the death rate, $\beta$, so that $n \equiv \eta-\beta$. The relative cohort weights evolve, in turn, according to:

$$
l(v, t) \equiv \frac{L(v, t)}{L(t)}=\eta e^{\eta(v-t)}, \quad t \geq v
$$

This expression then permits us to calculate the per-capita average value of consumption that represents the benchmark for the individual:

$$
c(t) \equiv \int_{-\infty}^{t} l(v, t) \bar{c}(v, t) d v .
$$

\footnotetext{
${ }^{11}$ It is straightforward to incorporate government consumption, taxes, and public debt into this framework. A task for future work is an analysis of the role of taxes and fiscal deficits in smoothing the economy's adjustment to demographic shocks.
} 
To derive the aggregate Euler equation, we differentiate (19) with respect to time to calculate the expression for $\dot{c}(t)$ :

$$
\begin{aligned}
\dot{c}(t) & \equiv l(t, t) \bar{c}(t, t)+\int_{-\infty}^{t} l(v, t) \dot{\bar{c}}(v, t) d v+\int_{-\infty}^{t} \dot{l}(v, t) \bar{c}(v, t) d v \\
& =\eta \bar{c}(t, t)+\int_{-\infty}^{t} l(v, t) \dot{\bar{c}}(v, t) d v-\eta \int_{-\infty}^{t} l(v, t) \bar{c}(v, t) d v \\
& =\int_{-\infty}^{t} l(v, t) \dot{\bar{c}}(v, t) d v-\eta[c(t)-\bar{c}(t, t)],
\end{aligned}
$$

where we have substituted for (18)-(19) to obtain (20). Since $\dot{\bar{c}}(v, t) \equiv(1-\alpha) \dot{\bar{x}}(v, t)+\alpha \dot{c}(t)$ from (3), the first term on the right-hand side of (20) is simplified in the following way:

$$
\begin{aligned}
\int_{-\infty}^{t} l(v, t) \dot{\bar{c}}(v, t) d v & =(1-\alpha) \int_{-\infty}^{t} l(v, t) \dot{\bar{x}}(v, t) d v+\alpha \int_{-\infty}^{t} l(v, t) \dot{c}(t) d v \\
& =(1-\alpha)[r(t)-\rho] \int_{-\infty}^{t} l(v, t) \bar{x}(v, t) d v+\alpha \dot{c}(t) \int_{-\infty}^{t} l(v, t) d v \\
& =(1-\alpha)[r(t)-\rho] x(t)+\alpha \dot{c}(t)
\end{aligned}
$$

where we substitute for (5) to obtain the second equality of (21). The third equality of (21) follows from the definition of $x(t)$ and the fact that cohort weights sum-up to unity. Thus, substitution of (21) into (20) and noting that $x(t)=c(t)$ holds in aggregate, yields the following economy-wide differential equation for consumption:

$$
\dot{c}(t)=[r(t)-\rho] c(t)-\frac{\eta}{1-\alpha} \cdot[c(t)-\bar{c}(t, t)] .
$$

Observe that the consumption externality —as parameterized by $\alpha$ — affects the magnitude of the second term in (22), known as the intergenerational turnover term, where $c(t)-\bar{c}(t, t)$ is the difference between average consumption and the consumption of new agents. This correction term, characteristic of the BY framework, takes into account the fact that older cohorts, enjoying greater levels of consumption due to greater stocks of wealth, are succeeded by new individuals, who start life without financial assets. As a consequence, the growth of consumption for the economy as a whole is less than the growth of consumption for each individual, even though each individual faces the same interest rate. Below, we detail implications of the consumption externality for the OLG steady-state. It remains to derive a more convenient expression for $c(t)-\bar{c}(t, t)$. Using (13) we find:

$$
\begin{aligned}
c(t) & =(\rho+\beta)[a(t)+h(t)]+\alpha[c(t)-(\rho+\beta) \Gamma(t)], \\
\bar{c}(t, t) & =(\rho+\beta) h(t)+\alpha[c(t)-(\rho+\beta) \Gamma(t)],
\end{aligned}
$$


where $\bar{a}(t, t)=0$, since new cohorts are born with no financial wealth. Combining (23)-(24), we obtain $[c(t)-\bar{c}(t, t)]=(\rho+\beta) a(t)$, which permits us to rewrite (22) as:

$$
\frac{\dot{c}(t)}{c(t)}=r(t)-\rho-\frac{\eta(\rho+\beta)}{1-\alpha} \cdot \frac{a(t)}{c(t)} .
$$

Using the cohort weights (18), aggregate financial assets, equal to $a(t) \equiv \int_{-\infty}^{t} l(v, t) \bar{a}(v, t) d v$, evolve according to:

$$
\begin{aligned}
\dot{a}(t) & \equiv l(t, t) \bar{a}(t, t)+\int_{-\infty}^{t} l(v, t) \dot{\bar{a}}(v, t) d v+\int_{-\infty}^{t} i(v, t) \bar{a}(v, t) d v \\
& =\int_{-\infty}^{t} l(v, t)[[r(t)+\beta-\eta] \bar{a}(v, t)+w(t)-\bar{c}(v, t)] d v \\
& =[r(t)-n] a(t)+w(t)-c(t),
\end{aligned}
$$

where, to obtain the second and third equalities in (26), we substitute, respectively, for the household's flow budget identity (4) and use the fact that $n \equiv \eta-\beta$.

\subsection{Macroeconomic equilibrium}

Having derived the relationships describing aggregate household behavior and using our previous descriptions of the firm sector, we are in a position to state the (per-capita) OLG macroeconomic equilibrium, which is given by: ${ }^{12}$

$$
\begin{aligned}
& \frac{\dot{c}(t)}{c(t)}=r(t)-\rho-\frac{\eta(\rho+\beta)}{1-\alpha} \cdot \frac{k(t)}{c(t)}, \\
& \dot{k}(t)=y(t)-c(t)-(\eta-\beta) k(t), \\
& r(t)=\varepsilon \frac{y(t)}{k(t)}, \quad w(t)=(1-\varepsilon) y(t), \\
& y(t)=Z_{0} k(t)^{\varepsilon}, \quad 0<\varepsilon<1 .
\end{aligned}
$$

The dynamics of aggregate consumption and capital are governed by (27)-(28), with $k(t)$ the predetermined and $c(t)$ the "jump" variable that responds to new information. The accumulation equation (28) for physical capital is obtained by letting $k(t) \equiv a(t)$, since physical capital is the only form of savings, and using the optimality conditions for the firm sector

\footnotetext{
${ }^{12}$ The standard RA model is recovered by setting $\eta=0$ and $\beta=-n$ in (27)-(28). Intuitively, in the RA case there are no new disconnected agents, and population growth shows up in the form of a negative $\beta$, i.e. an increase in the size of the dynastic family.
} 
stated in (29). Observe, furthermore, that (28) is stated in terms of the demographic variables, since $n \equiv \eta-\beta$. Equation (30) restates the per-capita production function.

We close this section with a description of the phase diagram of our OLG model. It follows from (27)-(28), that the $\dot{c}(t)=0$ and $\dot{k}(t)=0$ are given by:

$$
\begin{aligned}
& c(t)=\frac{\eta(\rho+\beta)}{\rho(1-\alpha)} \cdot \frac{k(t)}{\left(k(t) / k^{r a}\right)^{\varepsilon-1}-1} \equiv \Phi(k(t)), \\
& c(t)=Z_{0} k(t)^{\varepsilon}-(\eta-\beta) k(t),
\end{aligned}
$$

where $k^{r a}=\left(\varepsilon Z_{0} / \rho\right)^{1 /(1-\varepsilon)}$ is the long-run value of the capital stock in the standard RA framework and where we have substituted for $y(t)=Z_{0} k(t)^{\varepsilon}$ in (32). The corresponding slopes of these relationships equal:

$$
\begin{aligned}
& \left.\frac{d c(t)}{d k(t)}\right|_{\dot{c}(t)=0}=\frac{\Phi(k(t))}{k(t)}\left[1+\frac{(1-\varepsilon)\left(k(t) / k^{r a}\right)^{\varepsilon-1}}{\left(k(t) / k^{r a}\right)^{\varepsilon-1}-1}\right]>0, \text { for } 0 \leq k(t) \leq k^{r a}, \\
& \left.\frac{d c(t)}{d k(t)}\right|_{\dot{k}(t)=0}=\varepsilon Z_{0} k(t)^{\varepsilon-1}-(\eta-\beta) \gtreqless 0, \quad \text { as } \varepsilon Z_{0} k(t)^{\varepsilon-1} \gtreqless \eta-\beta,
\end{aligned}
$$

and are illustrated in Figure 1. In Figure 1 the (unique) intersection of the $\dot{c}(t)=0$ and $\dot{k}(t)=0$ isoclines determines the (initial) long-run values, $k^{b y}$ and $c^{b y}$, of the capital stock and consumption, where "by" denotes the Blanchard-Yaari framework. Note in Figure 1 that we also illustrate the corresponding long-run values of capital and consumption in the RA setting, which depicts the standard result that the long-run values of the capital stock and consumption in the RA framework exceed their BY counterparts, $k^{k r}>k^{b y}$ and $c^{k r}>c^{b y}$ (although both fall short of the Golden-Rule values, $k^{g r}$ and $c^{g r}$ ). ${ }^{13}$ Furthermore, observe that while the $\dot{k}(t)=0$ locus is independent of preferences-including the agent's attitude toward status - the $\dot{c}(t)=0$ locus is a function, among others, of the relative consumption parameter $\alpha .{ }^{14}$ In contrast, both the $\dot{c}(t)=0$ and $\dot{k}(t)=0$ isoclines are functions of the demographic parameters $\eta$ (the birth rate) and $\beta$ (the death rate). We employ log-linearized versions of this diagram in section 5 to analyze the short and long-run effects of status preference and demographic disturbances.

\footnotetext{
${ }^{13}$ Figure 1 is drawn under the (reasonable) assumption that $\rho>n$. In the OLG model this assumption is not necessary, i.e. a saddle-point stable equilibrium materializes to the right of $k^{g r}$ if $\rho<n$ (dynamic inefficiency). In contrast, in the RA model, $\rho<n$ is a necessary condition for saddle-point stability.

${ }^{14}$ If, however, labor supply is endogenous, then the $\dot{k}(t)=0$ isocline depends on preferences.
} 


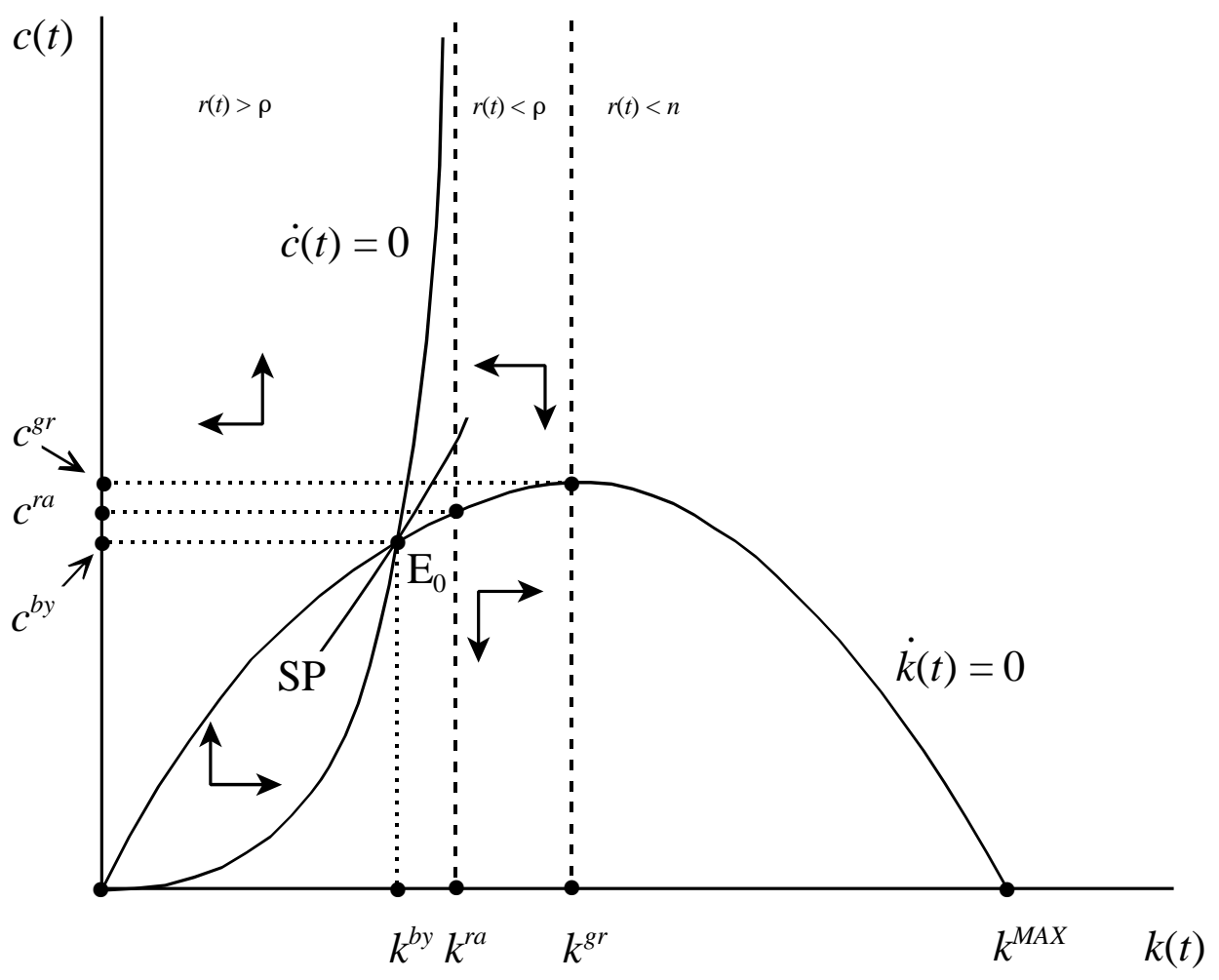

Figure 1: Phase Diagram 


\section{Log-Linearization and Model Solution}

\subsection{Log-Linearization}

In order to calculate the solution of the model, we must linearize the macroeconomic equilibrium derived above in (27)-(30), employing the following notation: $\tilde{y}(t) \equiv d y(t) / y$, $\tilde{k}(t) \equiv d k(t) / k, \tilde{c}(t) \equiv d c(t) / c, \tilde{r}(t) \equiv d r(t) / r, \tilde{w}(t) \equiv d w(t) / w, \tilde{\eta} \equiv d \eta / \eta, \tilde{\beta} \equiv d \beta / \beta$, $\tilde{\alpha} \equiv d \alpha /(1-\alpha), \dot{\tilde{k}}(t) \equiv d \dot{k}(t) / k$, and $\dot{\tilde{c}}(t) \equiv d \dot{c}(t) / c$. The log-linearized equilibrium then corresponds to:

$$
\begin{aligned}
& \dot{\tilde{c}}(t)=(r-\rho)\left[\tilde{c}(t)-\tilde{k}(t)-\tilde{\alpha}-\tilde{\eta}-\frac{\beta}{\rho+\beta} \tilde{\beta}\right]+r \tilde{r}(t), \\
& \dot{\tilde{k}}(t)=\frac{r}{\varepsilon}\left[\tilde{y}(t)-\omega_{C} \tilde{c}(t)\right]-n \tilde{k}(t)-\eta \tilde{\eta}+\beta \tilde{\beta}, \\
& \tilde{y}(t)=\tilde{w}(t), \quad \tilde{y}(t)-\tilde{k}(t)=\tilde{r}(t), \quad \tilde{y}(t)=\varepsilon \tilde{k}(t),
\end{aligned}
$$

where $n \equiv \eta-\beta, \omega_{C} \equiv c / y$ and $\omega_{A} \equiv r k / y=\varepsilon$.

\subsection{Model Solution}

Solving equations (33)-(34), the dynamic system for the capital stock and consumption can be written as follows:

$$
\left[\begin{array}{c}
\dot{\tilde{c}}(t) \\
\dot{\tilde{k}}(t)
\end{array}\right]=\Delta\left[\begin{array}{l}
\tilde{c}(t) \\
\tilde{k}(t)
\end{array}\right]-\left[\begin{array}{l}
\gamma_{c} \\
\gamma_{k}
\end{array}\right],
$$

where the Jacobian matrix and the vector of (time invariant) exogenous shocks are given, respectively, by: ${ }^{15}$

$$
\begin{aligned}
& \Delta \equiv\left[\begin{array}{ll}
\delta_{11} & \delta_{12} \\
\delta_{21} & \delta_{22}
\end{array}\right] \equiv\left[\begin{array}{cc}
r-\rho & -r(1-\varepsilon)-(r-\rho) \\
-\frac{r \omega_{C}}{\varepsilon} & r-n
\end{array}\right], \\
& {\left[\begin{array}{l}
\gamma_{c} \\
\gamma_{k}
\end{array}\right] \equiv\left[\begin{array}{c}
(r-\rho)\left[\tilde{\alpha}+\tilde{\eta}+\frac{\beta}{\rho+\beta} \tilde{\beta}\right] \\
\eta \tilde{\eta}-\beta \tilde{\beta}
\end{array}\right] .}
\end{aligned}
$$

\footnotetext{
${ }^{15}$ Note that both the birth and death rates enter negatively in the $\dot{\tilde{c}}(t)$ equation. In contrast, while the birth rate $\eta$ is a negative shift parameter in the $\dot{\vec{k}}(t)$ equation, the death rate $\beta$ enters positively.
} 
The system described by (36) is saddle-point stable, with $\operatorname{det} \Delta<0$ and the corresponding eigenvalues given by $-\lambda_{1}<0$ and $\lambda_{2}>0$. Evaluating the dynamic system in steadystate equilibrium, it is straightforward to calculate the long-run effects of permanent status preference and demographic shocks on consumption and physical capital:

$$
\left[\begin{array}{c}
\tilde{c}(\infty) \\
\tilde{k}(\infty)
\end{array}\right]=\Delta^{-1}\left[\begin{array}{l}
\gamma_{c} \\
\gamma_{k}
\end{array}\right]
$$

The next step in analyzing the adjustment of the economy is to compute the initial response of consumption, $\tilde{c}(0)$. To do so, we calculate the Laplace transform of (36), assuming that physical capital evolves from an initial predetermined stock, $\tilde{k}(0)=0$. The specific procedure is outlined in the appendix and yields the following (equivalent) expressions for $\tilde{c}(0)$ :

$$
\tilde{c}(0)=\mathcal{L}\left\{\gamma_{c}, \lambda_{2}\right\}+\frac{\delta_{12}}{\lambda_{2}-\delta_{22}} \mathcal{L}\left\{\gamma_{k}, \lambda_{2}\right\}=\mathcal{L}\left\{\gamma_{c}, \lambda_{2}\right\}+\frac{\lambda_{2}-\delta_{11}}{\delta_{21}} \mathcal{L}\left\{\gamma_{k}, \lambda_{2}\right\}
$$

where $\mathcal{L}\left\{\gamma_{i}, s\right\} \equiv \int_{0}^{\infty} \gamma_{i}(t) e^{-s t} d t$ is the Laplace transform of the time path for $\gamma_{i}(t)$. Finally, the transitional solution paths for consumption and capital correspond to:

$$
\left[\begin{array}{l}
\tilde{c}(t) \\
\tilde{k}(t)
\end{array}\right]=\left[\begin{array}{l}
\tilde{c}(0) \\
0
\end{array}\right] e^{-\lambda_{1} t}+\left[\begin{array}{l}
\tilde{c}(\infty) \\
\tilde{k}(\infty)
\end{array}\right]\left[1-e^{-\lambda_{1} t}\right],
$$

where, again, the solution method is described in the appendix, and where we have used the fact that the Laplace transform of the shock terms take the form $\mathcal{L}\left\{\gamma_{i}, s\right\}=\gamma_{i} / s$ for $i=c, k$, since, as indicated, we consider only unanticipated, permanent, time-invariant disturbances to the status preference and demography parameters. Below, we also illustrate the dynamic effects on post-shock newborn agents. It follows from the discussion regarding equation (25) that newborn consumption can be written as $\bar{c}(t, t)=c(t)-(\rho+\beta) k(t)$. Log-linearizing this expression, we obtain:

$$
\tilde{\bar{c}}(t, t)=\frac{c}{\bar{c}(0)} \tilde{c}(t)-\frac{k}{\bar{c}(0)}[(\rho+\beta) \tilde{k}(t)+\beta \tilde{\beta}],
$$

where $c, \bar{c}(0)$, and $k$ are the initial steady-state values for, respectively, per-capita consumption, newborn consumption, and the per-capita capital stock. 


\section{Comparative Dynamics}

Employing the results stated in the previous section, we now analyze the dynamic response of aggregate consumption and physical capital to status preference, birth rate, and mortality rate disturbances. We illustrate the transitional adjustment of the economy by using phase diagrams based on the dynamic system (36) and supplement these findings with numerical simulations of the transitional paths given in (41). We initially set the benchmark parameters for this exercise as follows: ${ }^{16}$

$$
\alpha=0.0, \quad \beta=0.005, \quad \eta=0.01, \quad \varepsilon=0.2, \quad r=0.05, \quad Z_{0}=1 .
$$

\subsection{Change in the Status Parameter}

Letting $\tilde{\alpha}>0$ and $\tilde{\eta}=\tilde{\beta}=0$ in (39), the long-run effect of an increase in the parameter describing the importance of status equals:

$$
\tilde{c}(\infty)=(r-\rho)(r-n) \cdot \frac{\tilde{\alpha}}{\operatorname{det} \Delta}<0, \quad \tilde{k}(\infty)=(r-\rho) \frac{r \omega_{C}}{\varepsilon} \cdot \frac{\tilde{\alpha}}{\operatorname{det} \Delta}<0,
$$

where det $\Delta<0$ and $r>n$. According to (43), a rise in $\alpha$ lowers both the level of consumption and the physical capital stock in the steady-state equilibrium. This result stands in sharp contrast to the findings of Liu and Turnovsky (2005) in the context of the RA model with exogenous employment. There, (see Proposition 1) the steady state of the economy was independent of consumption externalities. Our OLG relationships in (43) show, on the other hand, that an increase in the preference weight for relative consumption permanently lowers economic activity, even if work effort is given, as it is in our model. ${ }^{17}$ A change in $\alpha$ leads to an adjustment in the long-run equilibrium because it affects the importance of the generational turnover term in the Euler equation given above in (27). Higher values of $\alpha$, corresponding to greater degrees of jealousy, increase the importance of the generational turnover effect, which tends to lower the long-run values of consumption and physical capital.

\footnotetext{
${ }^{16}$ Our initial benchmark parameterization implies a capital-output ratio of 4 , a value not too far from empirical estimations, since $y$ represents net output. We use the rate of time preference as a calibration parameter and obtain $\rho=0.0478$. The consumption share is $\omega_{C}=0.98$ and the characteristic roots are $-\lambda_{1}=-0.080$ and $\lambda_{2}=0.127$.

${ }^{17}$ Clearly, if $r=\rho$, our results in (43) collapse to the RA case.
} 
Evaluating either expression in (40) for $\tilde{\alpha}>0$ and $\tilde{\eta}=\tilde{\beta}=0$, we calculate the initial jump in consumption:

$$
\tilde{c}(0)=\frac{r-\rho}{\lambda_{2}} \cdot \tilde{\alpha}>0
$$

which is unambiguously positive. The adjustment of consumption and the capital stock can be illustrated in the phase diagram in Figure 2(a). The rise in $\alpha$ causes the $\dot{\tilde{c}}(t)=0$ isocline to shift to the left, while the $\dot{\tilde{k}}(t)=0$ locus is unaffected by this exogenous disturbance. This leads to a shift in the long-run equilibrium from $E_{0}$ to $E_{1}$, which corresponds, as a indicated, to a decline on $\tilde{c}(\infty)$ and $\tilde{k}(\infty)$. The initial increase in consumption is depicted by the jump in the dynamic system from point $\mathrm{E}_{0}$ to point $\mathrm{A}$ in Figure 2(a), with $(\tilde{c}(t), \tilde{k}(t))$ proceeding down the (new) saddle path SP from point A to point $E_{1}$. The phase diagram analysis is confirmed by the numerical simulation of the adjustment paths of the model, which is calculated for an increase in $\alpha$ from its benchmark value of 0 to 0.5 . In other words, we simulate an increase in jealousy. The numerical simulations illustrated in Figures 2(c)(d) illustrate the initial jump as well as the long-run decline in consumption, along with the gradual decumulation of physical capital. Finally, in Figure 2(b) we illustrate the effects on newborn consumption, $\tilde{\tilde{c}}(t, t)$, as given in (42) above. Interestingly, despite the fact that per capita consumption falls in the long run, consumption by newborns remains above its initial steady-state value, both during transition and in the new steady state.

\subsection{Fall in the Birth Rate}

Here, we set $\tilde{\eta}<0$ and $\tilde{\alpha}=\tilde{\beta}=0$ in (39), with the long-run multipliers corresponding to:

$$
\begin{aligned}
& \tilde{c}(\infty)=[(r-\rho)(r+\beta)+\eta r(1-\varepsilon)] \cdot \frac{\tilde{\eta}}{\operatorname{det} \Delta}>0, \\
& \tilde{k}(\infty)=(r-\rho)\left[\frac{r \omega_{C}}{\varepsilon}+\eta\right] \cdot \frac{\tilde{\eta}}{\operatorname{det} \Delta}>0 .
\end{aligned}
$$

Clearly, the results in (45)-(46) imply that a permanent drop in the birth rate results in a greater level of consumption and physical capital. As indicated above, this demographic shock affects both the $\dot{\tilde{c}}(t)=0$ and the $\dot{\tilde{k}}(t)=0$ isoclines of the phase diagram in Figure 3(a), such that the former isocline shifts to the right, while the latter locus shifts to the left, responses that result in a new steady-state equilibrium at point $\mathrm{E}_{1}$, corresponding to higher values of $\tilde{c}(\infty)$ and $\tilde{k}(\infty)$. 
(a) phase diagram

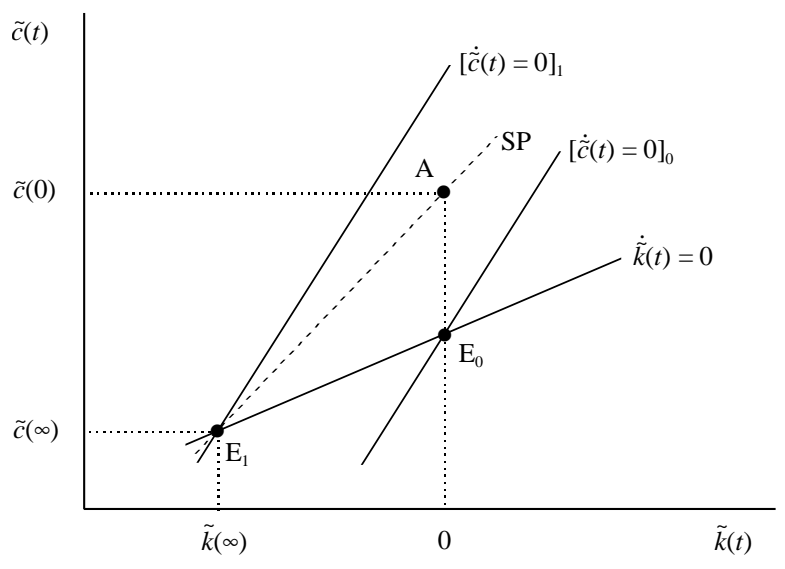

(c) consumption $(\tilde{c}(t))$

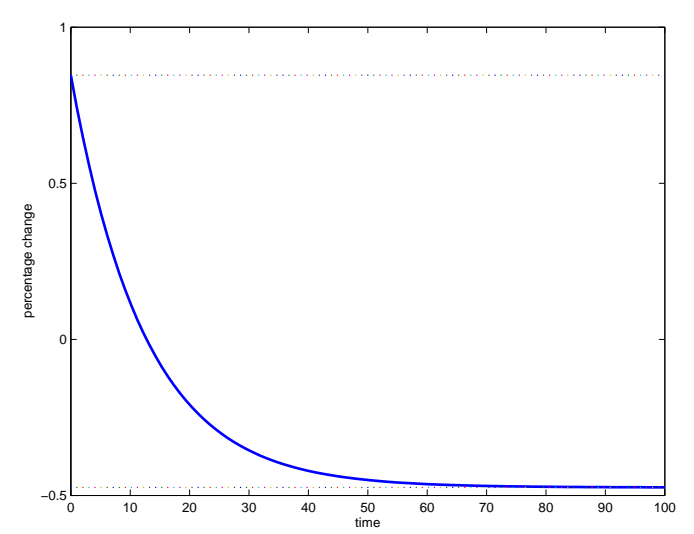

(b) consumption newborns $(\tilde{\bar{c}}(t, t))$

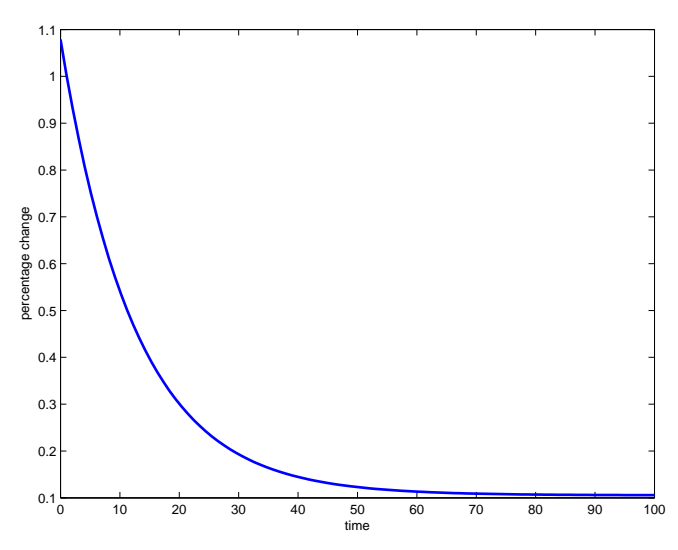

(d) capital stock $(\tilde{k}(t))$

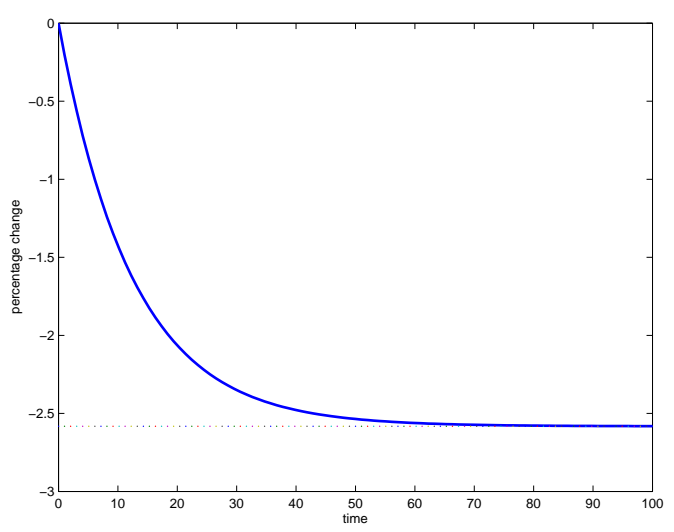

Figure 2: Increase in $\alpha$ from 0 to 0.5 
For this shock the initial jump in consumption, employing (40), equals:

$$
\tilde{c}(0)=\left[\frac{(r-\rho)\left(\lambda_{2}+\beta\right)-\eta r(1-\varepsilon)}{\lambda_{2}-(r-n)}\right] \cdot \frac{\tilde{\eta}}{\lambda_{2}},
$$

which is ambiguous in sign. In Figure 3(a) we illustrate the case in which $\tilde{c}(0)$ rises to point A on the new stable saddle path SP. Along SP, both consumption the capital stock increase to the new, long-run equilibrium. In the numerical simulation of this shock-which depicts the dynamic response to a fall in the birth rate $\eta$ (from $1 \%$ to $0.5 \%$ per annum) and in Figures $3(\mathrm{c})-(\mathrm{d})$ - the initial jump in consumption is positive, with the paths of consumption and the capital stock tracking those derived from our analytical model. In Figure 3(b), the consumption by newborns rises monotonically. In sum, a fall the birth rate $\eta$ has dynamic implications that are opposite from an increase in the relative consumption parameter $\alpha$, a result that follows from the fact that a lower birth rate implies that the generational turnover effect of the BY framework is less important. Equally, however, our previous results have shown that if agents care strongly about relative consumption ( $\alpha$ close to unity), then the generational turnover effect is crucial, even if the economy experiences a declining birth rate.

\subsection{Decline in the Mortality Rate}

To determine the steady-state implications of a permanent decline in the mortality rate, we set $\tilde{\beta}<0$ and $\tilde{\alpha}=\tilde{\eta}=0$ in (39) and compute the following long-run multipliers, given by:

$$
\begin{aligned}
& \tilde{c}(\infty)=[(r-\rho)(r-n)-(\rho+\beta)[r(1-\varepsilon)+r-\rho]] \cdot \frac{\beta}{\rho+\beta} \cdot \frac{\tilde{\beta}}{\operatorname{det} \Delta}, \\
& \tilde{k}(\infty)=(r-\rho)\left[\frac{r \omega_{C}}{\varepsilon}-(\rho+\beta)\right] \cdot \frac{\beta}{\rho+\beta} \cdot \frac{\tilde{\beta}}{\operatorname{det} \Delta}>0 .
\end{aligned}
$$

Whilst the effect on consumption is ambiguous in sign, the capital stock increases as a result of a longevity boost provided $\alpha$ is not too negative, i.e. admiration is not too strong. ${ }^{18}$ The initial jump in consumption, equal to:

$$
\tilde{c}(0)=-\frac{\tilde{\beta}}{\lambda_{2}} \frac{\beta}{\rho+\beta}\left[-(r-\rho)+\frac{(\rho+\beta)[r(1-\varepsilon)+(r-\rho)]}{\lambda_{2}-(r-n)}\right],
$$

\footnotetext{
${ }^{18}$ The term in square brackets on the right-hand side of (49) is positive. Note first that $r \omega_{C} / \varepsilon=c / k$. It follows from, respectively, (9) and (23) that steady-state human wealth and per capita consumption:$$
h=\frac{(1-\varepsilon) y}{r+\beta}>0, \quad c=(\rho+\beta) \frac{k+h}{1-\gamma},
$$$$
\text { where } \gamma \equiv \alpha(r-\rho) /(r+\beta)<1 \text {. Provided } \alpha \text { is not too negative, it follows that } c / k>\rho+\beta \text {. }
$$ 
(a) phase diagram

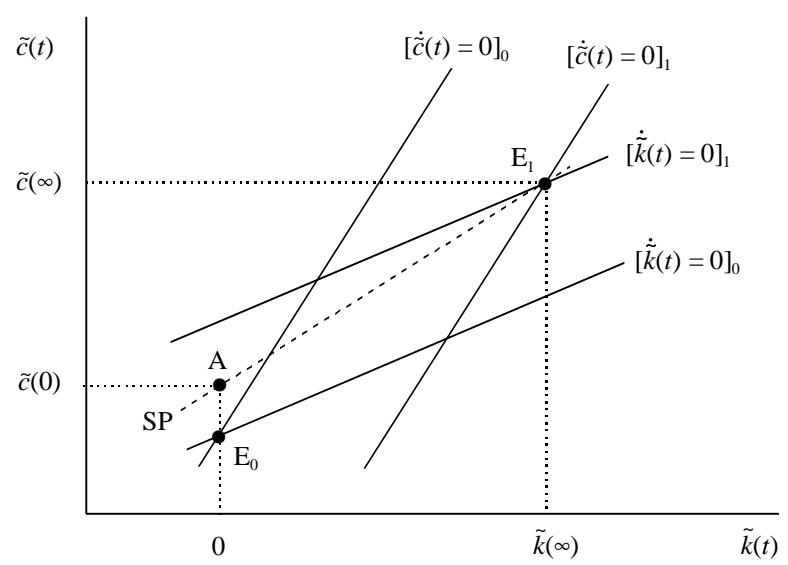

(c) consumption $(\tilde{c}(t))$

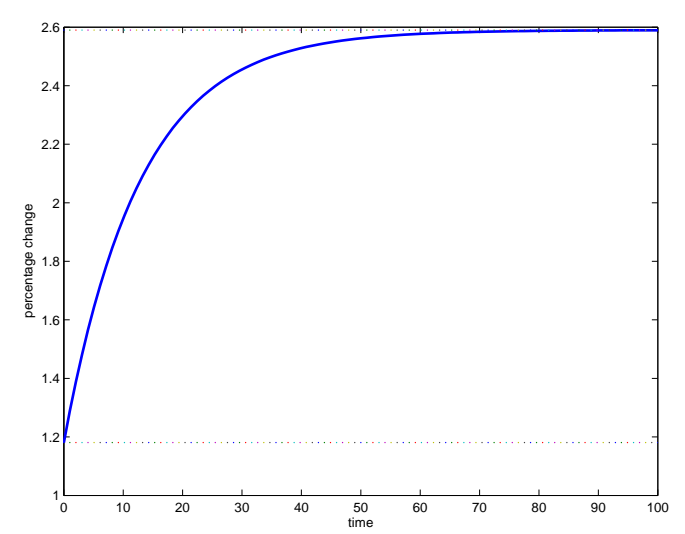

(b) consumption newborns $(\tilde{\bar{c}}(t, t))$

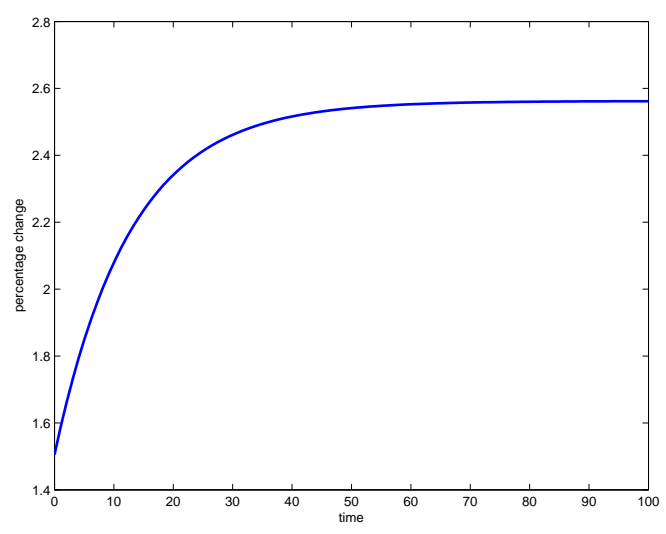

(d) capital stock $(\tilde{k}(t))$

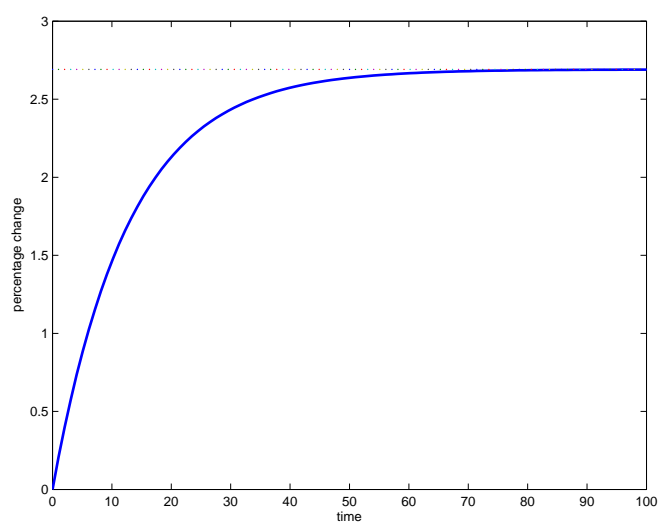

Figure 3: Decrease in $\eta$ from $1 \%$ to $0.5 \%$ per annum 
can be either positive or negative. The long-run ambiguity is due to the fact that both isoclines in the phase diagram in Figure 4(a) shift to the right subsequent to a fall in the mortality rate. In Figure 4(a) we illustrate the plausible case in which the rightward shift in the $\dot{\tilde{c}}(t)=0$ isocline dominates the rightward shift in the $\dot{\tilde{k}}(t)=0$ locus, which results in a new equilibrium at point $\mathrm{E}_{1}$ with lower long-run consumption $\tilde{c}(\infty)$, but higher physical capital $\tilde{k}(\infty)$. The latter response is quite intuitive, since the fall in the mortality encourages agents, since they live longer, to accumulate more assets. Turning to our numerical simulations for the case in which $\beta$ falls (from $0.5 \%$ to $0.1 \%$ per annum), we show in Figure 4 (c) that consumption initially declines before partially recovering in the transition to the steady state, a response also illustrated in the phase diagram. Figure 4(b) shows that newborn consumption falls as a result of the longevity boost.

\section{Conclusions and Extensions}

The goal of this paper is to merge two recent strands in the macroeconomic literature: the OLG framework and the work that seeks to investigate the implications of the quest for status. Our principle motivation in adopting the OLG approach with demographic variables is to develop a model of consumption externalities in which differences between individuals do not disappear in equilibrium. In other words, we wish to investigate the properties of a model in which agents are not "too equal", as they are in the RA setting. Employing the BY version of the basic OLG framework, we are able to overturn the recent result of Liu and Turnovsky (2005) regarding the long-run implications of consumption externalities: the latter permanently affect the steady state of the economy, even if employment is fixed. Indeed, if agents as a whole become more "jealous", then the rat race in our model leads to a long-run decline in aggregate consumption and the capital stock.

Rather than reiterating the rest of our findings, let us briefly indicate some possible extensions of this model. One is to introduce distortionary taxation with endogenous labor supply and consider the resulting welfare implications in a setting with consumption externalities. The recent work of Calvo and Obstfeld (1988) in calculating welfare effects in an OLG framework would be of assistance in this task. Furthermore, extending the model to an open economy context would permit us to consider the effects of a preference for relative 
(a) phase diagram

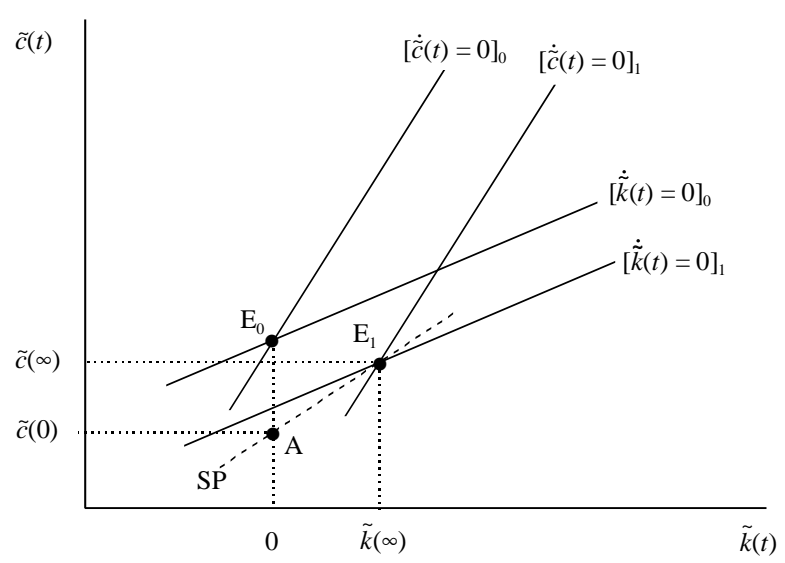

(c) consumption $(\tilde{c}(t))$

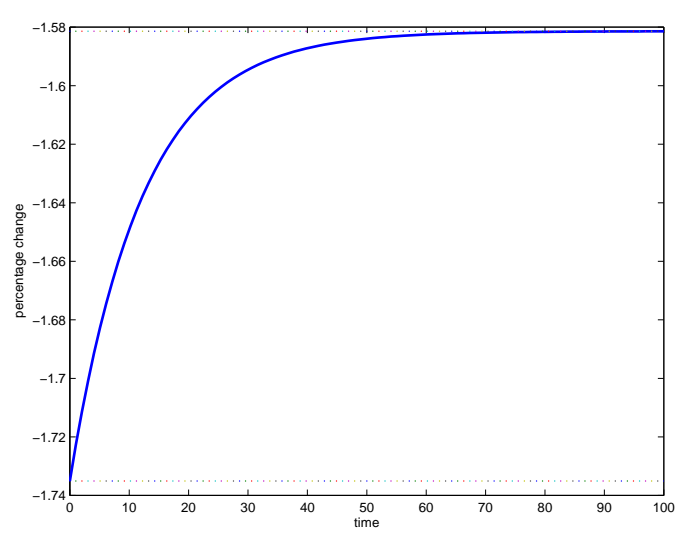

(b) consumption newborns $(\tilde{\bar{c}}(t, t))$

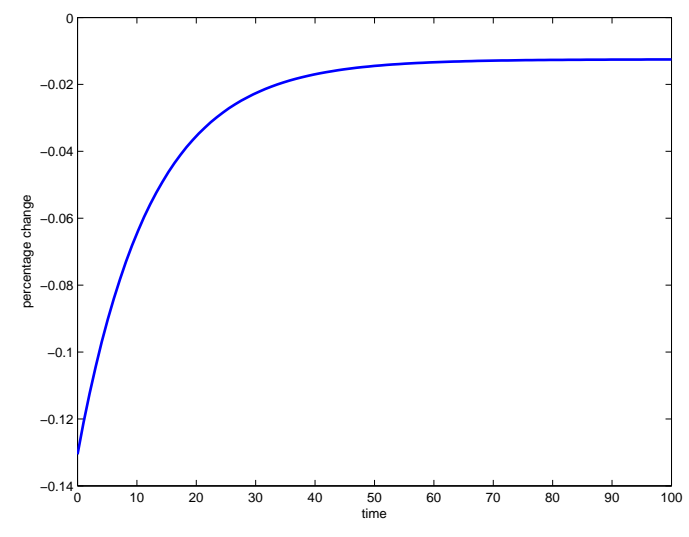

(d) capital stock $(\tilde{k}(t))$

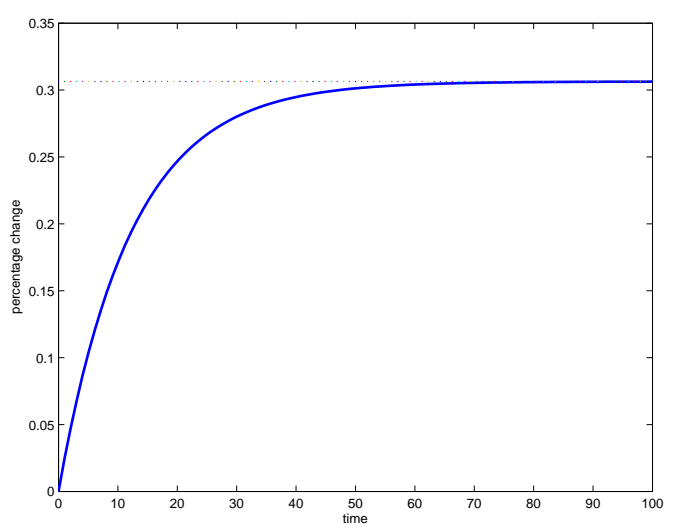

Figure 4: Decrease in $\beta$ from $0.5 \%$ to $0.1 \%$ per annum 
consumption on, for example, the current account dynamics. Finally, incorporating production externalities as well as consumption externalities would allow us to compare and contrast the implications of these two, distinct distortions in an OLG setting.

\section{Appendix}

\section{Derivation of the Expression for $\tilde{c}(0)$}

Taking the Laplace transform of (36) and imposing $\tilde{k}(0)=0$, we obtain:

$$
\Lambda(s)\left[\begin{array}{c}
\mathcal{L}\{\tilde{c}, s\} \\
\mathcal{L}\{\tilde{k}, s\}
\end{array}\right]=\left[\begin{array}{l}
\tilde{c}(0)-\mathcal{L}\left\{\gamma_{c}, s\right\} \\
-\mathcal{L}\left\{\gamma_{k}, s\right\}
\end{array}\right],
$$

where $\Lambda(s) \equiv s I-\Delta$, such that characteristic roots of $\Delta$ are $-\lambda_{1}<0$ (stable) and $\lambda_{2}>0$ (unstable). We next state the following lemma regarding the solutions to the characteristic polynomial, $\Psi(s) \equiv \operatorname{det} \Lambda(s)$.

Lemma A.1 The characteristic roots $-\lambda_{1}$ and $\lambda_{2}$ are solutions to $\Psi(s)=0$. Since the model is saddle-point stable $(|\Delta|<0)$, we find: (i) $\lambda_{2}>\delta_{22} \equiv r-n$;

Proof: Clearly, $\Psi(0)=|\Delta|<0$ (by saddle-point stability) and $\Psi\left(\lambda_{2}\right)=0$ (by definition). It follows that $\lambda_{2}>\delta_{22} \Longleftrightarrow \Psi\left(\delta_{22}\right)<0$. By substitution we find that $\Psi\left(\delta_{22}\right)=-\delta_{12} \delta_{21}<0$.

By pre-multiplying both sides of (A.1) by $\Lambda(s)^{-1} \equiv \operatorname{adj} \Lambda(s) /\left[\left(s+\lambda_{1}\right)\left(s-\lambda_{2}\right)\right]$ we obtain the following expression in Laplace transforms

$$
\left(s+\lambda_{1}\right)\left[\begin{array}{c}
\mathcal{L}\{\tilde{c}, s\} \\
\mathcal{L}\{\tilde{k}, s\}
\end{array}\right]=\frac{1}{s-\lambda_{2}} \operatorname{adj} \Lambda(s)\left[\begin{array}{l}
\tilde{c}(0)-\mathcal{L}\left\{\gamma_{c}, s\right\} \\
-\mathcal{L}\left\{\gamma_{k}, s\right\}
\end{array}\right],
$$

where adj $\Lambda(s)$ is the adjoint matrix of $\Lambda(s)$ :

$$
\operatorname{adj} \Lambda(s) \equiv\left[\begin{array}{cc}
s-\delta_{22} & \delta_{12} \\
\delta_{21} & s-\delta_{11}
\end{array}\right]
$$

In order to eliminate the instability originating from the positive (unstable) characteristic $\operatorname{root}\left(\lambda_{2}>0\right)$, the jump in consumption at impact $(\tilde{c}(0))$ must correspond to a value such 
that the numerator of (A.2) equals zero for $s=\lambda_{2}$ (at this value of $s$ the denominator is also zero) [see Judd (1998), pp. 459-460]. This yields the general expression for $\tilde{c}(0)$ :

$$
\operatorname{adj} \Lambda\left(\lambda_{2}\right)\left[\begin{array}{l}
\tilde{c}(0)-\mathcal{L}\left\{\gamma_{c}, \lambda_{2}\right\} \\
-\mathcal{L}\left\{\gamma_{k}, \lambda_{2}\right\}
\end{array}\right]=\left[\begin{array}{l}
0 \\
0
\end{array}\right],
$$

where we observe that adj $\Lambda\left(\lambda_{2}\right)$ has rank 1 , because $\lambda_{2}$ is a distinct eigenvalue of $\Lambda(s)$. Hence, either row of (A.4) can be used to compute $\tilde{c}(0)$. Using (A.3)-(A.4), we obtain solution (40) for the initial response of consumption stated in the main text:

$$
\tilde{c}(0)=\mathcal{L}\left\{\gamma_{c}, \lambda_{2}\right\}+\frac{\delta_{12}}{\lambda_{2}-\delta_{22}} \mathcal{L}\left\{\gamma_{k}, \lambda_{2}\right\}=\mathcal{L}\left\{\gamma_{c}, \lambda_{2}\right\}+\frac{\lambda_{2}-\delta_{11}}{\delta_{21}} \mathcal{L}\left\{\gamma_{k}, \lambda_{2}\right\}
$$

\section{A.3 Solution for the Transitional Path of $\tilde{c}(t)$ and $\tilde{k}(t)$}

To solve explicitly for the transitional paths of consumption and physical capital, we combine (A.2) and (A.4) and find:

$$
\begin{aligned}
\left(s+\lambda_{1}\right)\left[\begin{array}{c}
\mathcal{L}\{\tilde{c}, s\} \\
\mathcal{L}\{\tilde{k}, s\}
\end{array}\right]= & {\left[\begin{array}{c}
\tilde{c}(0)-\mathcal{L}\left\{\gamma_{c}, s\right\} \\
-\mathcal{L}\left\{\gamma_{k}, s\right\}
\end{array}\right] } \\
& +\frac{1}{s-\lambda_{2}} \cdot \operatorname{adj} \Lambda\left(\lambda_{2}\right)\left[\begin{array}{c}
\mathcal{L}\left\{\gamma_{c}, \lambda_{2}\right\}-\mathcal{L}\left\{\gamma_{c}, s\right\} \\
\mathcal{L}\left\{\gamma_{k}, \lambda_{2}\right\}-\mathcal{L}\left\{\gamma_{k}, s\right\}
\end{array}\right] .
\end{aligned}
$$

The relationships (A.5) and (A.6) constitute the general solution in terms of Laplace transforms of the dynamic system (36). As we indicate in section 4.2, we next use the fact that the Laplace transform disturbance terms correspond to $\mathcal{L}\left\{\gamma_{i}, s\right\}=\gamma_{i} / s$ for $i=c, k$, since shocks to $\tilde{\alpha}, \tilde{\eta}$, and $\tilde{\beta}$ are, by assumption, unanticipated, permanent, and time-invariant. Applying this to (A.6) and rearranging, we obtain the following:

$$
\left[\begin{array}{l}
\mathcal{L}\{\tilde{c}, s\} \\
\mathcal{L}\{\tilde{k}, s\}
\end{array}\right]=\left[\begin{array}{l}
\tilde{c}(0) \\
0
\end{array}\right] \frac{1}{s+\lambda_{1}}+\left[\begin{array}{l}
\tilde{c}(\infty) \\
\tilde{k}(\infty)
\end{array}\right] \frac{\lambda_{1}}{s\left(s+\lambda_{1}\right)} .
$$

Finally, by inverting (A.7) and noting $\mathcal{L}\left\{e^{-\lambda_{1} t}, s\right\}=1 /\left(s+\lambda_{1}\right)$ and $\mathcal{L}\left\{1-e^{-\lambda_{1} t}, s\right\}=\lambda_{1} /[s(s+$ $\left.\lambda_{1}\right)$ ], we obtain the solution for $(\tilde{c}(t), \tilde{k}(t))$ given in the main text in equation (41):

$$
\left[\begin{array}{l}
\tilde{c}(t) \\
\tilde{k}(t)
\end{array}\right]=\left[\begin{array}{l}
\tilde{c}(0) \\
0
\end{array}\right] e^{-\lambda_{1} t}+\left[\begin{array}{l}
\tilde{c}(\infty) \\
\tilde{k}(\infty)
\end{array}\right]\left[1-e^{-\lambda_{1} t}\right] .
$$




\section{References}

Abel, A.B. (1990). "Asset Prices under Habit Formation and Catching up with the Joneses", American Economic Review 80(2), 38-42.

Abel, A. B., (2005). “Optimal Taxation When Consumers Have Endogenous Benchmark Levels of Consumption", Review of Economic Studies, 72(1), 21-42.

Alverez-Cuadrado, F., Montiero, G., and S. J. Turnovsky (2004). “Habit Formation, Catching Up with the Joneses, and Economic Growth", Journal of Economic Growth 9(1), 47-80.

Bettendorf, L.J.H. and Heijdra, B.J. (2006). “Population Aging and Pension Reform in a Small Open Economy with Non-Traded Goods", Journal of Economic Dynamics and Control 30, 2389-2424.

Blanchard, O. (1985). "Debt, Deficits, and Finite Horizons", Journal of Political Economy 91, 589-610.

Bovenberg, A.L. and B.J. Heijdra (1998). “Environmental Abatement and Intergenerational Distribution", Environmental and Resource Economics 23, 45-84.

Buiter, W.H. "Fiscal Policy in Open Interdependent Economies", in Economic Policy in Theory and Practice, ed. A. Razin and E. Sadka, Macmillan, London, 1987.

Calvo, G.A. and M. Obstfeld (1988). “Optimal Time-Consistent Fiscal Policy with Finite Lifetimes", Econometrica 56, 411-432.

Corneo, C. and O. Jeanne (1997). "On Relative Wealth Effects and the Optimality of Growth", Economics Letters 54 (1), 87-92.

Corneo, G. and O. Jeanne (2001a). "On Relative Wealth Effects and Long-Run Growth", Research in Economics 55, 349-358.

Corneo, G., and O. Jeanne, (2001b). "Status, the Distribution of Wealth, and Growth", Scandinavian Journal of Economics 103(2), 283-293.

Diamond, P. A. (1965). "National Debt in a Neoclassical Growth Model", American Economic Review 55(5), 1126-1150. 
Dupor, B. and W.F. Liu (2003). "Jealousy and Equilibrium Overconsumption", American Economic Review 93(1), 423-428.

Easterlin, R. "Does Economic Growth Improve the Human Lot? Some Empirical Evidence", In Nations and Households in Economic Growth: Essays in Honor of Moses Abramowitz, ed. P.A. David and M.W. Reder, Academic Press, New York, 1974.

Easterlin, R. (1995). “Will Raising Incomes Increase the Happiness of All?", Journal of Economic Behavior and Organization 27(1), 35-48.

Fisher, W. H. (2004). "Status Preference, Wealth, and Dynamics in the Open Economy", German Economic Review 5(3), 335-355.

Fisher, W. H. and F. X. Hof (2000). "Relative Consumption, Economic Growth, and Taxation", Journal of Economics 72(3), 241-262.

Fisher, W. H. and F. X. Hof (2005a). "Status Seeking in the Small Open Economy", Journal of Macroeconomics 27(2), 209-232.

Fisher, W. H. and F. X. Hof (2005b). “The Quest for Status and Endogenous Labor Supply: the Relative Wealth Framework", Institute for Advanced Studies, Vienna, Economic Series \#181.

Frank, R. H. (1985). “The Demand for Unobservable and Other Nonpositional Goods”, American Economic Review 75, 101-116.

Frank, R. H. (1997) “The Frame of Reference as a Public Good," Economic Journal 107(445) (1997):1832-47.

Frenkel, J.A. and A. Razin (1986). "Fiscal Policies in the World Economy", Journal of Political Economy 34, 564-594.

Futagami, K., and A. Shibata (1998). "Keeping one Step Ahead of the Joneses: Status, the Distribution of Wealth, and Long Run Growth", Journal of Economic Behavior and Organization 36(1), 93-111.

Galí, J. (1994). “Keeping Up with the Joneses. Consumption Externalities, Portfolio Choice, and Asset Prices", Journal of Money, Credit, and Banking 26(1), 1-6. 
Grossmann, V., (1998). “Are Status Concerns Harmful for Growth?”, FinanzArchiv 55 (3), 357-73.

Heijdra, B.J. and J.E. Ligthart (2006). “The Macroeconomic Dynamics of Demographic Shocks", Macroeconomic Dynamics 10, 349-370.

Heijdra, B.J. and W.E. Romp (2006a). "Ageing and Growth in a Small Open Economy", Working Paper \# 1740, CESifo, München.

Heijdra, B.J. and W.E. Romp (2006b). "Retirement, Pensions, and Ageing", University of Groningen: download from: http://www.heijdra.org/ward3.pdf.

Judd, K.L. Numerical Methods in Economics, MIT Press, Cambridge, MA, 1998.

Liu, W.F. and S.J. Turnovsky (2005). “Consumption Externalities, Production Externalities, and the Accumulation of Capital", Journal of Public Economics 89, 1097-1129.

Layard, R. (1980). “Human Satisfactions and Public Policy", Economic Journal 90 (1980), 73750.

Ljungqvist, L. and H. Uhlig (2000). “Tax Policy and Aggregate Demand Management Under Catching Up with the Joneses", The American Economic Review 90, 356-66.

Obstfeld, M. and K. Rogoff. "The Intertemporal Approach to the Current Account", in Handbook of International Economics, vol. 3, ed. G. M. Grossman and K. Rogoff, North-Holland, Amsterdam, 1995.

Oswald, A. J. (1997). “Happiness and Economic Performance”, Economic Journal 107(445), $1815-1831$.

Rauscher, M. (1997). “Conspicuous Consumption, Economic Growth, and Taxation”, Journal of Economics 66 (1), 35-42.

Ryder, H. E. and G. M. Heal (1973). “Optimal Growth with Intertemporally Dependent Preferences", Review of Economic Studies 40(1), 1-31.

Turnovsky, S. J. and G. Monteiro (2007). “Consumption Externalities, Production Externalities, and Efficient Capital Accumulation under Time Non-Separable Preferences", European Economic Review 51(2), 479-504. 
Van Long, N. and K. Shimomura (2004a). "Relative Wealth, Status-Seeking, and CatchingUp", Journal of Economic Behavior \& Organization 53, 529-542.

Van Long, N. and K. Shimomura (2004b). "Relative Wealth, Catching-up, and Economic Growth", in S. Dowrick, R. Pitchford, and S.J. Turnovsky, eds., Economic Growth and Macroeconomic Dynamics: Recent Developments in Economic Theory, New York: Cambridge University Press, 18-45.

Yaari, M. E. (1965). “Uncertain lifetime, Life Insurance, and the Theory of the Consumer", Review of Economic Studies 32(1), 137-150. 
Authors: Walter H. Fisher, Ben J. Heijdra

Title: Keeping up with the Ageing Joneses

Reihe Ökonomie / Economics Series 204

Editor: Robert M. Kunst (Econometrics)

Associate Editors: Walter Fisher (Macroeconomics), Klaus Ritzberger (Microeconomics)

ISSN: $1605-7996$

(C) 2007 by the Department of Economics and Finance, Institute for Advanced Studies (IHS),

Stumpergasse 56, A-1060 Vienna • 畺 +43 1 59991-0 • Fax +43 159991-555 • http://www.ihs.ac.at 
ISSN: 1605-7996 